\title{
Impact of Elevated Parathormone Levels on the Severity of Pulmonary Hypertension in Patients with End Stage Renal Disease Undergoing Hemodialysis
}

\begin{abstract}
CRISTINA TUDORAN ${ }^{1}$, MARIANA TUDORAN ${ }^{1 *}$, ANCUTA MATES ${ }^{2}$, GHEORGHE NICUSOR POP ${ }^{1}$, AHMED ABU-AWWAD ${ }^{1}$

${ }^{1}$ Victor Babes University of Medicine and Pharmacy, 2 Eftimie Murgu Sq., 300041, Timisoara, Romania

${ }^{2}$ County Clinical Emergency Hospital "Pius Branzeu", 156 Liviu Rebreanu Str., 300723, Timisoara, Romania

One of the most severe cardiovascular complications encountered in patients with end stage renal disease (ESRD) undergoing hemodialysis (HD) is pulmonary hypertension (PH). Secondary hyperparathyroidism (SHPTH) is supposed to be one of the contributing mechanisms responsible for the occurrence of $\mathrm{PH}$ in these patients. The aim of our study is to determine if the elevated values of intact parathormone (iPTH) are correlated with increased pulmonary vascular resistance $(P V R)$ in patients ESRD undergoing HD.Our study was conducted on 51 patients with ESRD undergoing HD. We assessed in all patients the levels of $i P T H$, as well as the systolic pulmonary arterial pressure (PAPs) and PVR by means of echocardiography. According to the levels of PAPs, patients were classified into two subgroups: 27 with 24 without PH.We documented a moderate correlation between iPTH and systolic pulmonary artery pressure (PAPs), respectively $P V R$ in patients with $P H$. In patients without $P H$ there were no significant correlations between iPAH and PVR, respectively PAPs.
\end{abstract}

Keywords: pulmonary hypertension, end stage renal disease, hemodialysis, parathormone

Pulmonary hypertension $(\mathrm{PH})$ represents a serious complication in patients with end stage renal disease (ESRD) undergoing hemodialysis (HD) [1]. According to WHO criteria, PH is defined by increased pressures in the pulmonary artery (PAP) of over $25 \mathrm{mmHg}$ at rest and this category of $\mathrm{PH}$ is assigned to group 5.4., with unclear and/or multifactorial mechanisms $[2,3]$. Current data regarding the prevalence of $\mathrm{PH}$ in $\mathrm{HD}$ patients are conflicting presenting values ranging from $23 \%$ (4) to $58,9 \%$ [5].

The pathophysiology of this type of $\mathrm{PH}$ is a debated topic in the medical literature $[6,7]$. One of the first theories assumed that $\mathrm{PH}$ is the result of the chronically increased blood flow through the arterio-venous fistulas (AVF), used as an access for $\mathrm{HD}$, but several other vasoconstrictive and vasoproliferative processes play an important role. These contributing mechanisms are: vasoconstriction of the pulmonary vasculature due to an imbalance between vasodilator/vasoconstrictor mediators [8], as well as vascular calcifications with thickening of pulmonary arteries, induced by secondary hyperparathyroidism (SHPTH) with alterations in calcium $(\mathrm{Ca})$ and phosphate $(\mathrm{P})$ metabolism $[9,10]$. Thereby, the occurrence of $\mathrm{PH}$ in patients with ESRD undergoing $\mathrm{HD}$, assumes alterations of the pulmonary microvasculature induced by uremic conditions leading to an increased precapillary pulmonary vascular resistance (PVR), followed by the development of $\mathrm{PH}[11]$.

Taking into account that SHPTH is frequently diagnosed in patients with ESRD undergoing HD and that it could be related to the occurrence of $\mathrm{PH}$ precipitating the evolution of these patients to irreversible heart failure and death, it is important to consider this association and to evaluate these patients timely, by means of echocardiography. This method offers the possibility to estimate left and RV function, pulmonary artery pressure (PAPs) and PVR accurately, without the risks of invasive procedures, like right heart catheterization $[12,13]$.

The aim of this study is to analyze, in patients with ESRD, the association between PAP, documented by means of echocardiography, with the elevated PTH levels, as well as the impact of other factors like the elevated PVR, anemia or the duration of HD on the development of PH.

\section{Experimental part}

SHPTH represents a significant biochemical abnormality in patients with ESRD [11]. Elevated parathormone (PTH) levels favor the entry of $\mathrm{Ca}$ into cells, disturbing $\mathrm{Ca}-\mathrm{P}$ homeostasis and determining the accumulation of Ca content in many

*email: mariana.tudoran@gmail.com 
tissues. It is possible that this state could also be correlated with the occurrence of pulmonary vascular calcification being responsible for the development of PH in HD patients. Many studies debated over the correlation between increased iPTH levels and $\mathrm{PH}$ in this category of patients [9].

Study population: Our study was conducted on 51 patients with ESRD due to a primary renal disease (chronic glomerulonephritis/nephrotic syndrome, polycystic kidney, nephrolithiasis, chronic pyelonephritis) undergoing HD in the Hemodialysis Department of our hospital and in an ambulatory Hemodialysis Center during a period of four years (1 July 2014 - 30 June 2018). There were 27 men and 24 women, aged between 39 and 65 years (mean age $=57.62 \pm 6.61$ years). All patients with $\mathrm{PH}$ of other etiology were excluded from our study group as well as, patients with ESRD representing a complication of primary hypertension or of diabetes mellitus, taking into account that this disease is associated with an increased cardiovascular morbidity.

Methods: All patients with ESRD included in our study underwent regular HD on maintenance basis, via permanent AVF. This therapy was started for more than 6 months before the inclusion in the study, with limits between 7 to 168 months, median 40 (15 to 57). High-flux HD was performed with highly tissue-compatible membranes using a standard dialysis fluid, three times a week, in sessions of about 4-hour. All patients were carefully evaluated to identify signs of overhydration and fluid retention, in order to preserve their optimal dry weight. Although 37 patients presented secondary hypertension, blood pressure values were controlled with drugs. Laboratory investigations, including serum urea, creatinine, serum $\mathrm{Ca}$ and $\mathrm{P}$, haemoglobin, haematocrit, and intact PTH (iPTH), were analysed in the same day with the echocardiographic exam.

Cardiological evaluation: all echocardiographic examinations were performed post dialysis, as soon as possible, when patients were at optimal dry weight, taking into account that several echocardiographic parameters are influenced by patients' hydration status [14]. Transthoracic echocardiography was performed with a Siemens echocardiograph, by the same skilled echocardiographist, in order to avoid inter-observer differences. Assessment of LV mass index (LVMI), ejection fraction (EF) by Simpson method, tricuspid annular plane systolic excursion (TAPSE), right atrial (RA), right ventricle (RV) size were determined in M-mode and 2-D echocardiography. Conventional Doppler echocardiography was used to assess the velocity of the tricuspid regurgitation (TRV), to estimate PAPs (based on the peak TRV, taking into account the estimated RA pressure) and the pulmonary vascular resistance (PVR) by dividing peak TRV to the tricuspid velocity integral $[12,13]$. We considered that PAPs values $\geq 35 \mathrm{mmHg}$ at rest, measured by Doppler echocardiography, indicate $\mathrm{PH}(\sim 12)$ with severity ranging from mild $(35-45 \mathrm{mmHg})$, moderate $(45-60 \mathrm{mmHg})$ to severe (over $60 \mathrm{mmHg})$ [12, 13]. Echocardiographicaly estimated PVR has been shown to provide a reliable non-invasive estimation of PVR [12]. A normal PVR is under 1.5 Wood Units (WU). In this study, we considered PVR of over 2 WU as elevated and over 3 WU as significant for the diagnosis of PH $[12,13,14,15]$. Assessment of AVF flow volume (FV) in $\mathrm{mL} / \mathrm{min}$, was performed with the same equipment, with a $7 \mathrm{MHz}$ linear probe, on a single longitudinal scan of the vessel, by using the cross-sectional area of the vessel $\left(\mathrm{cm}^{2}\right)$ and the mean velocity $(\mathrm{cm} / \mathrm{s})$ measured in pulsed Doppler at the site used to determine the area [16].

Statistical analysis: was performed using SPSS v.25.0 (Statistical Package for the Social Sciences, Chicago, IL, USA). Continuous variables were presented as mean and standard deviation (SD) or median and interquartile range (IQR), and categorical variables were presented as frequency and percentages. We performed descriptive and inferential statistics analysis to summarize the characteristics of the study population. The results of the normality test (Shapiro-Wilk) showed a non-Gaussian distribution, reason why we continued to use nonparametric tests. In order to highlight the prevailing etiopathogeny of PH, we analyzed the strength of a linear relationship between levels of PAPs and PVR, iPTH, Ca levels and the duration of HD, by using the Spearman's rank-order correlation. To compare patients with/without PH we used Mann-Whitney U test. To evaluate the distribution of PH in patients we applied the chi-squared test $(\chi 2)$. A p value of less than 0.05 was considered to indicate a statistically significant difference.

The study was approved by the Ethics Committee of our hospital and all patients signed a written informed consent.

\section{Results and discussions}

Our study group comprised 51 patients, 27 men and 24 women, aged between 39 and 65 years (mean age $=57.62 \pm 6.61$ years), with ESRD, receiving HD via permanent AVF, for 7 to 168 months, median 40 (15 to 57). Referring to the etiology of ESRD, 29 patients (56.86\%) had chronic glomerulonephritis, $9(17.64 \%)$ chronic pyelonephritis, 7 (13.72\%) polycystic kidney and $6(9.83 \%)$ nephrolithiasis. 38 patients $(74.5 \%)$ had SHPTH, with iPTH levels ranging from $62-475 \mathrm{pg} / \mathrm{mL}$, median (290 (200-400) and $43(84.31 \%)$ had anemia, 39 of them being treated with erythropoietin. The clinical characteristics and echocardiography data are presented in table 1.

LV hypertrophy, expressed by LVMI levels, was a common finding among our patients, being determined in $90.19 \%$ of cases (46 subjects). 27 patients (52.94\%), 16 men and 11 women, most of them with chronic glomerulonephritis (21 patients - 77.77\%), had PAPs values of over $35 \mathrm{mmHg}$ defining PH. Median values of PAPs were 46 (42 to 55) mmHg. 8 patients (29.62\%) had mild PH, 13 (48.14\%) moderate forms and 6 (22.22\%) presented severe PH. 24 patients (88.88\%) had 
pathological levels of PVR (over 2 WU) and 12 of them (44.44\%) had PVR over 3 WU. PH was absent only in 24 subjects $(47.05 \%)$ who had PAPs values under $35 \mathrm{mmHg}$.

In this study, we evidenced a prevalence of $\mathrm{PH}$ of 52.94\%. We documented a higher prevalence in patients with ESRD due to chronic glomerulonephritis and in those receiving HD over a longer time period. Thus, in the subset of participants with $\mathrm{PH}$, we determined a strong correlation between PAPs values and the duration of HD. No such correlation was documented in patients without $\mathrm{PH}$.

$\mathrm{PH}$ has been frequently described in HD patients, but the reported prevalence varied largely in various papers. The highest values, of 58.6\%, was sustained by Fabbian [5], followed by Mukhtar (56\%) (1), but, on the other hand, Thang, in a recent metaanalysis of 16 studies, comprising 7,112 patients with ESRD undergoing HD [4], reported an overall prevalence of $\mathrm{PH}$ of $23 \%$. These data are controversial because the analysed studies were heterogeneous with differences regarding inclusion criteria, monitored parameters and statistical methods.

Table 1

CLINICAL CHARACTERISTICS AND LABORATORY RESULTS IN THE STUDY GROUP

\begin{tabular}{|c|c|c|c|c|}
\hline \multirow{2}{*}{$\begin{array}{c}\text { Clinical, laboratory and } \\
\text { echocardiography results }\end{array}$} & \multicolumn{3}{|c|}{ Patients with ESRD } & $\begin{array}{c}\text { p value between } \\
\text { patients with and } \\
\text { without PH }\end{array}$ \\
\cline { 2 - 5 } & Total 51 & 27 with PH & 24 without PH & 0.887 \\
\hline Age (years) & $57.62 \pm 6.61$ & $57.48 \pm 5.96$ & $57.75 \pm 7.43$ & 0.115 \\
BMI (Kg/m $\left.{ }^{2}\right)$ & $24.7(23.5-26.5)$ & $24(23.45-25)$ & $25.5(23.7-26.7)$ & 0.362 \\
SBP (mmHg) & $140(140-150)$ & $140(140-150)$ & $140(131.2-150)$ & 0.924 \\
DBP (mmHg) & $90(80-95)$ & $90(80-95)$ & $90(81.25-95)$ & 0.137 \\
Heart Rate (HR) & $70(65-75)$ & $70(65-70)$ & $70(65.25-75)$ & $<0.001$ \\
iPTH (pg/mL) & $290(200-400)$ & $400(340-420)$ & $200(200-255)$ & $<0.001$ \\
Hb (g/dL) & $9.1(8.4-10)$ & $8.6(8-9)$ & $10(9.5-10.3)$ & 0.009 \\
Ht (\%) & $30.1(29.5-31)$ & $29.8(29.1-30.8)$ & $31(30-31.2)$ & $<0.001$ \\
Ca (mg/dL) & $9.3(9-9.8)$ & $9(8.8-9.2)$ & $9.8(9.52-10)$ & 0.089 \\
P (mg/dL) & $3.9(3.4-4)$ & $3.8(3.3-4)$ & $4(3.62-4.07)$ & $<0.001$ \\
AVF flow volume (mL/min) & $1000(950-1300)$ & $1150(1000-1410)$ & $980(892.5-1150)$ & $<0.001$ \\
Duration of HD (months) & $40(15-57)$ & $48(42-60)$ & $15.5(10.25-17)$ & 0.079 \\
LVMI (g/m $\left.{ }^{2}\right)$ & $130(115-140)$ & $135(120-150)$ & $127.5(110-140)$ & 0.03 \\
Rjection fraction (EF)\% & $50(49-55)$ & $50(45-55)$ & $50(50-55)$ & $<0.001$ \\
RV basal diameter (mm) & $32(28-38)$ & $38(33-42)$ & $28(27-31)$ & $<.001$ \\
PAPSE (\%) & $24(22-27)$ & $23(20-24)$ & $26.5(23-28)$ & $<0.001$ \\
PVR (WU) & $37(24-47)$ & $46(42-55)$ & $22.5(15.4-28.75)$ & $<0.001$ \\
\hline
\end{tabular}

Legend: $E S R D=$ end stage renal disease; $P H=$ pulmonary hypertension; $H D=$ hemodialysis; $A V F=$ arterio-venous fistula: $B M I=$ body mass index; $S B P=$ systolic blood pressure; $D B P=$ diastolic blood pressure; $i P T H=$ intact parathormone; $H b=$ haemoglobin; Ht=haematocrit; $C a=$ calcium; $P=$ phosphorus; $L V M I=l e f t$ ventricular mass index; $R V=$ right ventricle; TAPSE=tricuspid annular plane systolic excursion; PAPS = estimated systolic pressure in the pulmonary artery; $P V R=$ pulmonary vascular resistance; $W U=$ Wood Units.
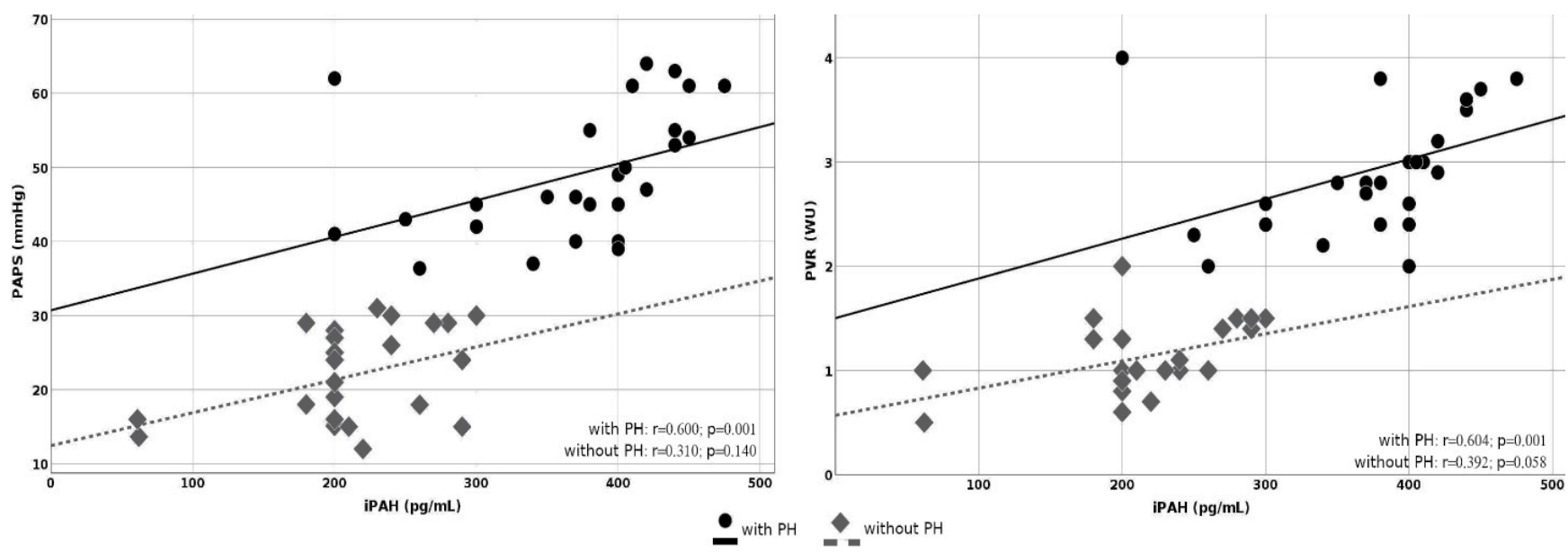

Legend: $P A P s=$ estimated systolic pressure in the pulmonary artery; $P V R=$ pulmonary vascular resistance; $i P A H=$ intact parathormone levels. Fig. 1. Correlations between PAPs, respectively PVR and levels of iPAH

The statistical analyze of our results, by using Spearman's test, evidenced in patients with PH, a strong correlation between PAPs and PVR levels $(r=0.933, p<0.001)$ and with the duration of $\mathrm{HD}(\mathrm{r}=0.702, \mathrm{p}<0.001)$. For these patients, we highlighted moderate correlations between PAPs, respectively PVR and iPAH levels $(r=0.60, p=0.001$, respectively 
$\mathrm{r}=0.604, \mathrm{p}=0.001$ ), figure 1. In patients without $\mathrm{PH}$ the results were not so conclusive. The correlations between PAPs and PVR values were moderate $(\mathrm{r}=0.527, \mathrm{p}<0.008)$ and there were no significant correlations between these parameters and iPAH levels ( $r=0.31, p=0.14$, respectively $r=0.392, p=0.058)$, figure 1 .

In our study we documented an increased prevalence of SHPTH (74.5\%), with increased iPTH levels, associated with anemia in $84.31 \%$ cases. $71.05 \%$ of these patients were diagnosed with $\mathrm{PH}$ and we documented moderate correlation between iPAH levels and PAPs, respectively PVR values. These findings sustain the hypothesis that SHPTH could be one of the mechanisms that affects the pulmonary microvasculature resulting in increased PVR and it could explain the development of PH in patients with ESRD. The role of the increased PVR in the pathogenesis of PH is discussed in the medical literature [17-21]. Increased precapillary PVR due to the alterations of pulmonary microvasculature and obliteration of small vessels, together with vasoconstrictive and vasoproliferative processes, may represent the main pathophysiological mechanism for the development of PH. In their study Suresh et al [20, 21], debate the role of the endothelial dysfunction and of the impaired PVR, as well as of the systemic inflammation [22-26].

SHPTH is a frequent complication in patients with ESRD undergoing HD. The possibility that they can develop HP is frequently ignored until it ultimately results in irreversible heart failure and death [22-26]. For this reason, especially in patients with SHPTH it is important to perform screening echocardiography since this method offers the possibility of an accurate diagnosis at low costs and reduced risks for the patient in order to detect PH timely, and to correct the imbalances of P-Ca metabolism. Patients diagnosed with PH should be monitored by regular echocardiography and in terms of iPTH levels. If possible they and could be offered alternative methods of dialysis, reversal of the AV fistula or they may be proposed earlier for renal transplant in order to reduce or even reverse $\mathrm{PH}$.

\section{Conclusions}

SHPTH was frequently diagnosed in our patients with ESRD undergoing HD. The increased prevalence of PH determined by means of echocardiography in these patients could be related to the altered Ca-P metabolism since we evidenced moderate correlations between iPTH and PAPs levels.

\section{References}

1. MUKHTAR, K.N., MOHKUMUDDIN, S., MAHMOOD, S.N. Pak J Med Sci., 30, nr. 6, 2014, p. 1319.

2. GALIE, N., HUMBERT, M., VACHIERY, J.L., GIBBS, S., LANG, I., TORBICKI, A., et al. European Heart Journal, 37 , no. 1, 2016 , p. 67. 3.TUDORAN C., TUDORAN M., PARV F., POP G.N., ABU-AWWAD A., VLAD M., BALAS M. Rev.Chim.(Bucharest), 70, nr.4, 2019 , p. 1328. 4. TANG, M., BATTY, J.A., LIN, C., FAN, X., CHAN, K.E., KALIM, S. AJKD., 72, nr. 1, 2018, p. 75.

5. FABBIANI, F. Int J Nephrol., nr. 2, 2011, p. 89.

6. KOSMADAKIS, G., AGUILERE, D., CARCELES, O., DA COSTA, C.E., BOLETIS, I. Journal Renal Failure, 35, nr. 4, 2013 , p. 514.

7. GENCTOY, G., ARIKAN, S., GEDIK, O. Int Urol Nephrol., 47, nr. 2, 2015, p. 353.

8. TUDORAN, M., TUDORAN, C., VLAD, M., BALAS, M.., ABU-AWWAD, A., POP, G.N., REV.CHIM.(Bucharest), 70, no. 4, 2019 , p.1372.

9. MOUSAVI, S.S.B., TAMADON, M.R., NASRI, H., ARDALAN, M.R. J of Parathyroid Disease, 2, nr. 2, 2014 , p. 71.

10. TUDORAN, M., TUDORAN, C., CIOCARLIE, T., POP, G.N., BERCEANU-VADUVA, M.M., VELIMIROVICI, D.E., ABU-AWWAD, A., BERCEANU-VADUVA, D.M., Mat. Plast., 56, no. 1, 2019, p. 37.

11.HEIDARI, M., MARDANI, S., BARADARAN, A. Journal of Parathyroid Disease, 2, nr. 2, 2014, p. 78.

12. ABBAS, A.E., FRANEY, L.M., MARWICK, T., MAEDER, M.T., KAYE, D.M., VLAHOS, A.P., et al. JASE, 26, nr. 10, 2013 , p. 1170.

13. NAING, P., KUPPUSAMY, H., SCALIA, G., HILLIS, G.S., PLAYFORD, D. Heart, Lungs and Circulation, 26, nr. 4, 2017 , p. 323.

14. SAG, S., YESILBURSA, D., YILDIZ, A., DILEK K., ŞENTURK, T., SERDAR, O.A., AYDINLAR, A. Balkan Med J., nr.31, 2014, p. 239.

15. TUDORAN, M., TUDORAN, C., Nigerian Jornal of Clinical Practice, 19, nr. 6, 2016, p. 831.

16. ZAMBOLI, P., FIORINI, F., D’AMELIO, A., FATUZO, P., GRANATA, A. J Ultrasound, 17, nr. 4, 2014 , p. 253.

17. AFZAL, A., BHATTI, M.A., MANZOOR, S. J. College of Physicians and Surgeons Pakistan, 28, nr. 8, 2018 , p. 594.

18. THENAPPAN, T. Pulmonary circulation, 7, nr. 3, 2017, p. 567.

19. TUDORAN, C., TUDORAN, M., VLAD, M., BALAS, M., POP, G.N., PARV, F. Anatol J Cardiol., 20, nr. 3, 2018, p. 174.

20. SURESH, H., ARUN, B.S., MOGER, V., VIJAYALAXMI, P.B., MURALI, M.K., Indian J Nephrol., nr. 28, 2018 , p.127.

21. TUDORAN, M., GIURGI-ONCU, C., ANDOR, B., ABU-AWWAD, A., POP, G.N., BERCEANU-VADUVA, D., TUDORAN, C. Rev.Chim. (Bucharest), 70, no.5, 2019, p 1685.

22. ABU-AWWAD A, FOLESCU R, POP DL, MOTOC AGM, OPREA DM, TUDORAN M, ZAMFIR CL, FAUR CI, VERMESAN D, DELEANU BN, ANDOR BC, HARAGUS HG. Morphometric characteristics of fibrocartilaginous tissue in the herniated intervertebral disc. Rom J Morphol Embryol, 2019, 60(2): p.629

23. SELVARAJ, S., SHAH, S.J., OMMERBORN, M.J., CLARK, C.R., HALL, M.E., MENTZ, R.J., et al. Circ Heart Fail., 10, nr. 6, 2017 , p.1-8. 24. ABU AWWAD AHMED, PREJBEANU R., VERMESAN D., DELEANU B., IONITESCU M.., FLORESCU S., VLAD C.D., DUMITRASCU V., Dose Effect Of Local Betamethasone Injection In Low Back Pain, Rev.Chim.(Bucharest), 69, no. 9, 2018, p. 2382

25. ZHANG, Q., WANG, L., ZENG, H., LY, Y., HUANG, Y. BMC Nephrology, nr. 19, 2018, p. 70.

26. ABU AWWAD AHMED, PREJBEANU R., VERMESAN D., BRANEA I., DELEANU B., FLORESCU S., VLAD V. D., Blood Loss Of Pedicle Subtraction Osteotomy For Sagittal Imbalance Spinal Deformity, Rev.Chim.(Bucharest), 69, no. 12, 2018, p. 3680

Manuscript received: 1111.2019 